\title{
Extrinsic Defects in Amorphous Oxides: Hydrogen, Carbon, and Nitrogen Impurities in Alumina
}

\author{
Zhendong Guo, ${ }^{*}$ Francesco Ambrosio, and Alfredo Pasquarello \\ Chaire de Simulation à l'Echelle Atomique (CSEA), Ecole Polytechnique Fédérale de Lausanne (EPFL), CH-1015
}

Lausanne, Switzerland

(Received 9 October 2018; revised manuscript received 30 November 2018; published 15 February 2019)

We present a procedure for addressing extrinsic defects in amorphous oxides, in which the most stable defect configurations are identified through ab initio molecular dynamics in various charge states and studied through hybrid functional calculations. The protocol is further complemented with an electron counting scheme based on maximally localized Wannier functions, which allows one to identify the nominal charge state and the composition of the defect core unit. Here, we apply this approach to the study of hydrogen, carbon and nitrogen impurities in amorphous alumina $\left(a-\mathrm{Al}_{2} \mathrm{O}_{3}\right)$, a highly relevant material for technological applications. Hydrogen is found to be amphoteric with a thermodynamic $+1 /-1$ charge transition level lying at $\sim 4.6 \mathrm{eV}$ above the valence band maximum, in qualitative agreement with results obtained with crystalline models, but at a substantially different energy level. Hydroxyl groups are further shown to lead to the same defect states as observed for hydrogen. Application of our procedure to carbon and nitrogen impurities leads to structural configurations that are found to depend on the total charge set in the simulation cell. Through the adopted electron counting rule, we assess that carbon and nitrogen impurities are only found in neutral and in singly positive charge states, respectively. This indicates that neither carbon nor nitrogen give charge transition levels in the band gap, in strong contrast with results achieved for crystalline models. In addition, the defect core units are shown to incorporate a varying number of oxygen atoms, by which their formation energy depends on the oxygen chemical potential $\mu_{O}$. In oxygenpoor conditions, both the carbon and the nitrogen impurities favor bonding to $\mathrm{Al}$ atoms, while they tend to form single or double bonds with oxygen atoms as $\mu_{O}$ increases. Based on the band alignment of $a-\mathrm{Al}_{2} \mathrm{O}_{3}$ with three technologically relevant semiconductors ( $\mathrm{GaAs}, \mathrm{GaN}$ and $\alpha-\mathrm{Fe}_{2} \mathrm{O}_{3}$ ), we discuss the possible role of point defects in degrading the performance of electronic devices and in favoring hole transport across the oxide in water-splitting setups.

DOI: 10.1103/PhysRevApplied.11.024040

\section{INTRODUCTION}

Amorphous oxides are an important class of materials and have found numerous technological applications, e.g., as electron collection electrodes in organic solar cells [1], channel layers in transparent thin-film transistors [2,3], high-capacity negative electrodes in lithium batteries $[4,5]$ and resistance switching layers in non-volatile memory devices [6]. It is experimentally demonstrated that these oxides inevitably contain a large number of defects, either intentionally or unintentionally, as a result of the deposition process [7-11]. Therefore, there is considerable interest in understanding how defects, either intrinsic or extrinsic, affect the electronic properties, and consequently, the performance of the material in the various applications. The general understanding of defects in crystalline materials has progressed noticeably through a profitable interaction between experiment and theory, the latter having

\footnotetext{
*zhendong.guo@epfl.ch
}

evolved over the years and grown into relatively standard protocols for evaluating defect energies and concentrations $[12,13]$. However, the study of defects in amorphous oxides has lagged behind. Two types of approaches are typically followed. One approach consists in putting aside the disordered nature of the oxide and taking various crystalline phases as suitable models for the amorphous oxide. In an alternative approach, one adopts a truly disordered model structure of the amorphous oxide, for instance, as generated by a quench from the melt through molecular dynamics (MD). In the latter case, the actual defect investigation then follows the standard protocol developed for studying defects in crystalline materials. However, neither scheme fully captures the ability of the amorphous oxide to incorporate defects through structural rearrangements.

The study of defects in a model structure of the amorphous oxide requires the consideration of various aspects, which are not common to the study of defects in a crystalline solid. First, a variety of sites needs to be taken under consideration to properly account for the different chemical 
environments occurring in the amorphous system. This aspect is generally dealt with in a statistical manner by considering a set of defect configurations that encompass the diversity in the amorphous oxide. A second difficulty arises when extracting the proper energetics. It is then necessary to disentangle the energy associated with the defect from the relaxation energy of the amorphous structure, which is only partially captured in a model of finite size and is subject to change upon defect generation or charge transition. To minimize this effect, it has been proposed to introduce a cycling procedure to optimally capture the relaxation energy of the amorphous structure [14,15]. Third, the potential energy surface of amorphous materials can be rather complex with many local energy minima, so that the relaxation of a defect created in an amorphous model generally leads to a local minimum, which may differ significantly both in structure and in energy from the equilibrium configuration. The use of MD and thermal annealing cycles facilitates the exploration of the potential energy surface and generally leads to more stable defect configurations $[14,15]$. Fourth, the nominal charge state of an extrinsic defect can differ from the charge added to the simulation cell due to its (partial) localization on intrinsic defects. All these considerations indicate that the study of defects in an amorphous oxide requires particular care, which goes well beyond the trivial extension of the procedure generally applied to defects in crystalline materials. In particular, it also appears that it is recommended to have a deep understanding of the possible intrinsic defects before considering the investigation of extrinsic impurities.

As a case study, in this work, we focus on amorphous alumina $\left(a-\mathrm{Al}_{2} \mathrm{O}_{3}\right)$, an earth-abundant oxide with a wide electronic band gap, low-leakage current and a modest value of dielectric constant. For these reasons, $a-\mathrm{Al}_{2} \mathrm{O}_{3}$ is widely used in a variety of technological applications. These include gate dielectrics in metal-oxidesemiconductor (MOS) devices [16-20], coating layers for protecting cathodes in lithium-ion batteries from corrosion [21-23] and overlayers on hematite photoanodes for reducing the overpotential of the water splitting reaction [24]. In these applications, the atomic layer deposition (ALD) technique is often used to deposit $a-\mathrm{Al}_{2} \mathrm{O}_{3}$ [25-27]. The ALD procedure features metal-organic precursors, which always undergo incomplete decomposition due to lowtemperature growth conditions. This, in turn, leads to the incorporation of a sizeable number of impurities [28,29]. Concentrations up to 0.2 at. \% of carbon [8] and $\sim 5.0$ at. \% of nitrogen [9] have been detected. ALD processes also make use of water, thus giving non-negligible concentrations of hydrogen in the amorphous material [30]. However, despite clear evidence for the occurrence of such extrinsic impurities in $a-\mathrm{Al}_{2} \mathrm{O}_{3}$, much less is known about the effects of these defects on the electronic properties of the material. For instance, it is not clear whether such defects give rise to deep levels in the band gap that could lead to leakage channels, and thereby affect the performance of $a-\mathrm{Al}_{2} \mathrm{O}_{3}$ as an insulator in MOS devices. Similarly, given the large band gap of $a-\mathrm{Al}_{2} \mathrm{O}_{3}$ (6.1-7.0 $\mathrm{eV}$ [31-33]), it is unclear by what mechanism holes that are photogenerated in the valence band of hematite photoanodes migrate through the alumina overlayer in water splitting devices [24]. Point defects could underlie these observations and their possible role should hence be clarified.

While native defects in $a-\mathrm{Al}_{2} \mathrm{O}_{3}$ have been the object of several experimental and theoretical investigations $[15,34$ 38], far less attention has been devoted to extrinsic defects in the literature, especially in theoretical works. Indeed, theoretical studies on impurities, such as carbon, nitrogen and hydrogen have been carried out by taking into consideration only the crystalline phases of $\mathrm{Al}_{2} \mathrm{O}_{3}$ [39-44]. In particular, Choi et al. [39] investigated the defect levels associated with carbon and nitrogen impurities in $\alpha-\mathrm{Al}_{2} \mathrm{O}_{3}$. Carbon has been found to induce charge transition levels near the conduction-band edges of semiconductors such as III-As, Si and GaN, and has been indicated as a possible origin of border traps and/or leakage currents [7,45], while nitrogen was postulated to act as a source of negative fixed charge [39]. Interstitial hydrogen impurities in $\alpha$ and $\kappa-\mathrm{Al}_{2} \mathrm{O}_{3}$ have been reported to be amphoteric with a $+1 / 1$ defect level lying at 5.3-5.8 and $3.3 \mathrm{eV}$ above the respective valence band maxima (VBM) $[40,43,44]$. This very different location with respect to the VBM impairs the use of crystalline phases as models for the amorphous oxide. More generally, the crystalline phases differ from the amorphous one in structure, density and band gap [46], making it difficult to carry over results achieved for crystalline $\mathrm{Al}_{2} \mathrm{O}_{3}$ to the amorphous phase. Therefore, it is necessary to explicitly account for the disordered nature of the structure when addressing defects in $a-\mathrm{Al}_{2} \mathrm{O}_{3}$.

The combined use of $a b$ initio molecular dynamics simulations and hybrid-functional electronic-structure calculations has been successfully demonstrated in the study of intrinsic defects in $a-\mathrm{Al}_{2} \mathrm{O}_{3}$ [15]. In particular, oxygen vacancies and interstitials were addressed and it has been found that such defects do not give rise to any localized electronic state in $a-\mathrm{Al}_{2} \mathrm{O}_{3}$, unlike in crystalline phases of alumina. The amorphous structure is systematically able to assimilate the generated defect through structural rearrangements. The imbalance of oxygen simply leads to a nonstoichiometric compound in which the oxygen occurs in the form of $\mathrm{O}^{2-}$ ions.

In this work, we study extrinsic defects in amorphous alumina focusing on hydrogen, carbon and nitrogen impurities. We aim at describing the formation energies and the thermodynamic charge transition levels of stable defect states. To this end, we use a combination of ab initio molecular dynamics simulations and hybrid functional calculations. The charge state of the extrinsic defect is clearly defined in the case of hydrogen and is analogous 
to the descriptions achieved for crystalline phases. In the case of carbon and nitrogen impurities, our simulations reveal defect first-neighbor shells with a variety of compositions. To identify the nominal charge state of such extrinsic defects, we apply an electron counting rule based on maximally localized Wannier functions, and identify, on the basis of the local charge, the atoms of the amorphous system that should be considered inherent to the inserted impurity. We find that all the identified defect configurations are neutral for the carbon impurity and positively charged for the nitrogen impurity without any charge transition level in the band gap for either impurity. Furthermore, our scheme allows us to highlight that the most stable form of the defect depends on the oxygen chemical potential. Finally, we discuss the alignment of the identified defect levels with respect to the band edges of technologically relevant semiconductors.

This paper is organized as follows. In Sec. II, we describe the theoretical framework employed here for calculating defect formation energies, provide computational details and define the protocol used for generating defects in a model structure of $a-\mathrm{Al}_{2} \mathrm{O}_{3}$. The latter includes a cycling procedure to properly achieve the energetics of defects in amorphous oxides. In Sec. III, we present defect formation energies for extrinsic hydrogen, carbon and nitrogen impurities. The defect levels identified in $a-\mathrm{Al}_{2} \mathrm{O}_{3}$ are aligned in Sec. IV with respect to the band edges of $\mathrm{GaAs}, \mathrm{GaN}$ and $\alpha-\mathrm{Fe}_{2} \mathrm{O}_{3}$. Finally, we draw conclusions in Sec. V.

\section{METHOD}

\section{A. Defect formation energy}

The formation energy $E_{f}\left[X^{q}\right]$ of a defect $X$ in its charge state $q$ as a function of Fermi energy $\epsilon_{F}$ referred to the VBM is given by the following equation $[13,47]$ :

$$
\begin{aligned}
E_{f}\left[X^{q}\right]= & E_{\mathrm{tot}}\left[X^{q}\right]+E_{\mathrm{corr}}^{q}-E_{\mathrm{tot}}\left[\mathrm{Al}_{2} \mathrm{O}_{3}\right] \\
& -\sum_{i} n_{i} \mu_{i}+q\left[\epsilon_{F}+\epsilon_{v}+\Delta v_{0 / b}\right],
\end{aligned}
$$

where $E_{\text {tot }}\left[X^{q}\right]$ is the total energy of the supercell with a defect $X$ in the charge state $q, E_{\text {tot }}\left[\mathrm{Al}_{2} \mathrm{O}_{3}\right]$ is the total energy of bulk $a-\mathrm{Al}_{2} \mathrm{O}_{3}, n_{i}$ is the number of added or subtracted atoms of the species $i$ needed to create the defect $X$ and $\mu_{i}$ is the respective chemical potential. $\epsilon_{v}$ is the valence band maximum of bulk $a-\mathrm{Al}_{2} \mathrm{O}_{3}$. Here, unless stated otherwise, the chemical potentials of hydrogen $\left(\mu_{H}\right)$, nitrogen $\left(\mu_{N}\right)$ and oxygen $\left(\mu_{O}\right)$ are set to half the energy of an isolated hydrogen, nitrogen or oxygen molecule, respectively. The chemical potential of carbon is defined as $\mu_{C}=E_{\text {tot }}\left[\mathrm{CO}_{2}\right]-2 \mu_{O}$, where $E_{\text {tot }}\left[\mathrm{CO}_{2}\right]$ represents the energy of an isolated carbon dioxide molecule. The potential alignment term $\Delta v_{0 / b}$ accounts for the potential shift between the pristine bulk and the neutral defect calculation [13]. Finally, $E_{\text {corr }}^{q}$ corrects for finite-size effects due to the long-range nature of the Coulomb interaction, which affects charged systems under periodic boundary conditions (PBC). Here, we adopt the scheme proposed by Freysoldt, Neugebauer and Van de Walle (FNV) $[13,48]$. In the FNV framework, the electrostatic finite-size correction energy is expressed as follows:

$$
E_{\text {corr }}=E_{\text {latt }}-q \Delta_{q / 0},
$$

where $E_{\text {latt }}$ is the classical interaction energy of a Gaussian model charge distribution in a neutralizing background and $q \Delta_{q / 0}$ is a potential alignment term, which is related to the extent of the charge distribution. This term can be determined by comparing the electrostatic potential obtained from the model charge to the difference between the potentials of a charged and neutral defect in the densityfunctional-theory calculation at a large distance from the defect.

The formation energies vs $\epsilon_{F}$ also give the charge transition levels. For a transition between charge states $q$ and $q^{\prime}$, the charge transition level $\epsilon\left(q / q^{\prime}\right)$ corresponds to the specific value of $\epsilon_{F}$ for which the formation energies of the defect in the charge states $q$ and $q^{\prime}$ are equal: $E_{f}\left[X^{q}\right]=$ $E_{f}\left[X^{q^{\prime}}\right]$. This gives the following expression for $\epsilon\left(q / q^{\prime}\right)$ :

$$
\begin{aligned}
\epsilon\left(q / q^{\prime}\right)= & \frac{\left(E_{\mathrm{tot}}\left[X^{q}\right]-E_{\mathrm{tot}}\left[X^{q^{\prime}}\right]\right)+\left(E_{\mathrm{corr}}^{q}-E_{\mathrm{corr}}^{q^{\prime}}\right)}{q^{\prime}-q} \\
& -\left(\varepsilon_{v}+\Delta v_{0 / b}\right) .
\end{aligned}
$$

\section{B. Computational details}

In this work, we investigate all defects by using a combination of $a b$ initio MD simulations and hybrid functional calculations. All the calculations performed in our work are carried out with the freely available CP2K/QUICKSTEP package [49], which takes advantage of a combined atomic basis sets/plane waves approach. Analytical GoedeckerTeter-Hutter pseudopotentials [50,51] are used to treat core-valence interactions. We use a triple-zeta correlationconsistent polarized basis set (cc-pVTZ) [52] for $\mathrm{H}, \mathrm{O}$, $\mathrm{C}$, and $\mathrm{N}$ atoms, and the shorter range molecularly optimized double-zeta basis set with one polarization function (DZVP-MOLOPT-SR-GTH) [53] for Al atoms. A cut-off of $500 \mathrm{Ry}$ is employed for the plane waves. Structural relaxations and MD simulations are carried out within the generalized gradient approximation (GGA) through the use of the Perdew, Burke and Ernzerhof (PBE) functional [54]. It is well known that GGA functionals underestimate band gaps. This failure of GGA is particularly dramatic for materials with a wide band gap, such as $a-\mathrm{Al}_{2} \mathrm{O}_{3}$. Since the incorrect description of the band gap can also affect the accuracy of the defect energy levels, all electronic structure calculations in this work are performed with the HeydScuseria-Ernzerhof (HSE) hybrid functional $[55,56]$, upon 
the achievement of structural configurations at the PBE level. In particular, we set the fraction of Fock exchange $\alpha$ to 0.44 and keep the inverse screening length fixed at its default value $\left(\mu=0.11 \mathrm{bohr}^{-1}\right)$, in order to preserve the accuracy of the functional [57]. This computational setup correctly reproduces the experimental gap of $\alpha-\mathrm{Al}_{2} \mathrm{O}_{3}$ at zero temperature $(9.13 \mathrm{eV})[46,58]$. For the band gap of $a-\mathrm{Al}_{2} \mathrm{O}_{3}$, we then obtain $6.64 \mathrm{eV}$ in accord with the experimental range (6.1-7.0 eV) [31-33] and previous calculations $(6.67 \mathrm{eV})$ [46]. When the structure is relaxed at the HSE level, we find a decrease of about $1.3 \%$ in the lattice parameters of the supercell and a corresponding increase of the band gap by $0.2 \mathrm{eV}$. This effect is within the uncertainty of our density functional scheme and will be neglected in this work. Calculations within the hybrid functional scheme are carried out using the auxiliary density matrix method (ADMM) implemented in CP2K [59-61]. This method, which features the calculation of exchange integrals in a small auxiliary basis set, largely speeds up the otherwise computationally expensive calculations at the hybrid functional level.

\section{Model generation}

We use the model of $a-\mathrm{Al}_{2} \mathrm{O}_{3}$ generated in Ref. [46], which features an orthorhombic supercell containing $64 \mathrm{Al}$ and $96 \mathrm{O}$ atoms, with lattice constants of 11.47, 11.24, and $12.78 \AA$, corresponding to a mass density of 3.29 $\mathrm{g} / \mathrm{cm}^{3}$ in accord with the experimental range (3.05-3.65 $\mathrm{g} / \mathrm{cm}^{3}$ ) [62-64]. This bulk model has been produced via ab initio MD simulations through a quench from the melt. The obtained structure shows good agreement with neutron diffraction experiments $[46,62]$. Defect structures are generated by a two-step procedure. First, we identify available voids in the amorphous structure, in which the extrinsic impurity $(\mathrm{H}, \mathrm{C}$, or $\mathrm{N})$ is placed. For this, we carry out a Voronoi analysis, which determines the position and the size of the available voids. For each considered impurity and for each considered charge state, 10 such voids with radii between 1.7 and $2.5 \AA$ are selected and 10 different initial configurations are generated by placing the impurity at their centers. Next, each initial configuration is allowed to evolve through ab initio MD simulations in the NVT ensemble for a duration of $3 \mathrm{ps}$. The temperature is set at $1000 \mathrm{~K}$ through a Nosé-Hoover thermostat $[65,66]$. In this way, the extrinsic impurity can optimize its structural configuration on an affordable time scale. It should be noted that the barriers that can be overcome with such a temperature are just of the order of $0.1 \mathrm{eV}$. In our simulations, these barriers are overcome in a couple of picoseconds. Hence, the corresponding barriers should easily be overcome at typical experimental growth temperatures when much longer relaxation time scales of the order of minutes or hours are allowed. We then sample structural configurations at simulation times of $1,1.5,2,2.5$, and 3 ps from every MD trajectory and fully relax the structures until the forces are smaller than $10^{-4} \mathrm{Ha} / \mathrm{bohr}$. Among these five relaxed configurations, only the lowest-energy one is kept for further investigation, resulting in 10 models for each extrinsic species in a given charge state. During the MD runs, the structural rearrangement induced by the defect is always accompanied by a general relaxation of the amorphous structure. To minimize the influence of this effect on the defect formation energy, we carry out a cycling procedure, as proposed earlier in the study of defects in amorphous $\mathrm{HfO}_{2}$ [14] and $\mathrm{Al}_{2} \mathrm{O}_{3}$ [15]. In this procedure, we first remove the inserted impurity from its relaxed configuration and relax the resulting structure. Then, we reinsert the impurity and relax the structures again. The cycling is continued until the total energies of both the defective and the pristine bulk systems converge within $10^{-3} \mathrm{eV}$. In this procedure, we only retain the model when the final configuration for the pristine amorphous system shows an energy that is lower than its initial energy and a band gap that does not differ by more than $0.2 \mathrm{eV}$ from the initial one.

In our study, we consider only interstitial impurities, but in all possible charge states. Such a study comprehensively covers other defect generation schemes, such as those used when creating substitutional defects. In fact, substitutional defects lead to a modification of the relative amount of $\mathrm{Al}$ and $\mathrm{O}$ atoms, which can be accounted for by modifying the charge added to the simulation cell (cf. Ref. [15]). For instance, the case of a $\mathrm{C}$ impurity substitutional to $\mathrm{O}$ in the neutral charge state is equivalent to that of an interstitial $\mathrm{C}$ in the charge state -2 .

\section{EXTRINSIC DEFECTS}

\section{A. Hydrogen}

We first focus on hydrogen, which has been extensively investigated in crystalline $\mathrm{Al}_{2} \mathrm{O}_{3}[40-43]$, as well as in numerous other oxides $[14,42,43,67-73]$. In our calculation, three charge states are considered: $+1,0$, and -1 . Upon $\mathrm{MD}$, the $\mathrm{H}^{+}$is found to bond either to a twofold [Fig. 1(a)] or to a threefold coordinated $\mathrm{O}$ atom [Fig. 1(b)]. On average, configurations with attachments to twofold coordinated $\mathrm{O}$ atoms are found to be $0.75 \mathrm{eV}$ more stable than those involving threefold coordinated $\mathrm{O}$ atoms. Similarly, $\mathrm{H}^{-}$can form single bonds to $\mathrm{Al}$ atoms [Fig. 1(d)], but it can also bridge two $\mathrm{Al}$ atoms [Fig. 1(c)], with the latter configuration being $\sim 0.9 \mathrm{eV}$ more stable.

In order to investigate the stabilization effect resulting from the MD simulations, the configurations achieved by $\mathrm{MD}$ and by structural relaxation only are compared. For $\mathrm{H}^{+}$and $\mathrm{H}^{-}$, the achieved structural configurations show a similar first-neighbor coordination shell. However, a different description applies to the case of the neutral hydrogen atom $\left(\mathrm{H}^{0}\right)$. After structural relaxation without performing any $\mathrm{MD}, \mathrm{H}^{0}$ stays at the center of the void, minimizing 
(a)

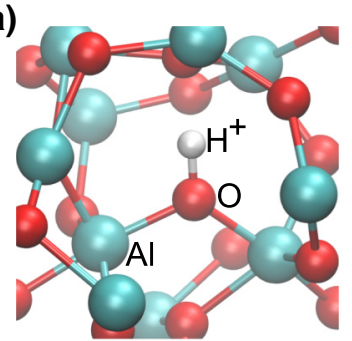

(c)

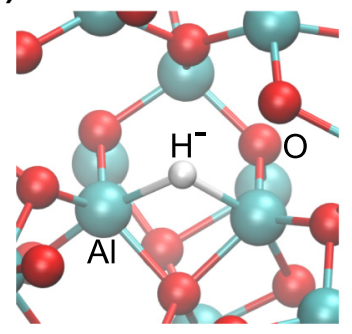

(b)

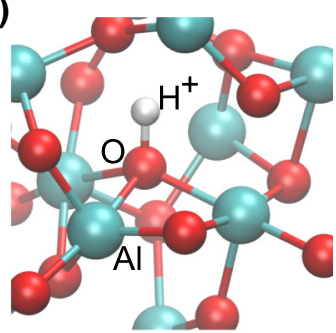

(d)

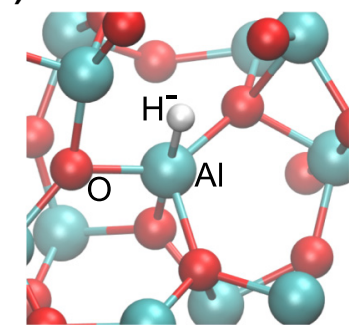

FIG. 1. Relaxed atomic configurations of $\mathrm{H}^{+}$, bonding (a) to a twofold coordinated $\mathrm{O}$ atom and (b) to a threefold coordinated $\mathrm{O}$ atom, and of $\mathrm{H}^{-}$(c) bridging two $\mathrm{Al}$ atoms and (d) bonding to a single $\mathrm{Al}$ atom. $\mathrm{Al}$ atoms are shown in cyan, $\mathrm{O}$ atoms in red, and $\mathrm{H}$ atoms in white.

the interactions with the surrounding atoms, as previously found in other oxides $[14,42,43]$. At variance, upon MD, the $\mathrm{H}$ atom bonds to an $\mathrm{O}$ atom [cf. Figs. 1(a) and (b)]. This implies that the neutral $\mathrm{H}$ atom undergoes oxidation and becomes positively charged $\left(\mathrm{H}^{+}\right)$. The missing electron has been donated to the conduction band (CB) of $a-\mathrm{Al}_{2} \mathrm{O}_{3}$, as attested by the delocalized nature of the highest occupied Kohn-Sham orbital (HOMO). In experiments, the detached electron may give rise to the formation of negatively charged defects. In any event, the present results clearly indicate that neutral $\mathrm{H}$ cannot occur in $a-\mathrm{Al}_{2} \mathrm{O}_{3}$.

The formation energies of $\mathrm{H}$ in $a-\mathrm{Al}_{2} \mathrm{O}_{3}$ are shown in Fig. 2(a) as a function of Fermi level for the charge states $+1,-1$, and 0 . For each charge state, we find that the average formation energies upon MD are lower than those achieved without MD by $\sim 0.6 \mathrm{eV}$, indicating that the MD runs significantly contribute to the stabilization of hydrogen impurities in amorphous oxide models. As found in numerous semiconductors and oxides [43,74], the stable states correspond to the charge states +1 and -1 . We also note that when the Fermi level is in the CB, the energy of $\mathrm{H}^{0}$ is higher than that of $\mathrm{H}^{+}$upon $\mathrm{MD}$, further supporting that $\mathrm{H}^{0}$ is unstable. Upon $\mathrm{MD}$, the $+1 /-1$ charge transition level is found in the gap of $a-\mathrm{Al}_{2} \mathrm{O}_{3}$ at $4.63 \mathrm{eV}$ above the VBM. Otherwise, when only structural relaxations are performed, this level is found at $4.65 \mathrm{eV}$, barely different from the case with MD. For both $\mathrm{H}^{+}$and $\mathrm{H}^{-}$, we also examine the density of states (DOS) and do not observe any single-particle energy level in the band gap of $a-\mathrm{Al}_{2} \mathrm{O}_{3}$. In Fig. 2(b), the calculated defect level due to hydrogen is compared with previous calculations for crystalline phases

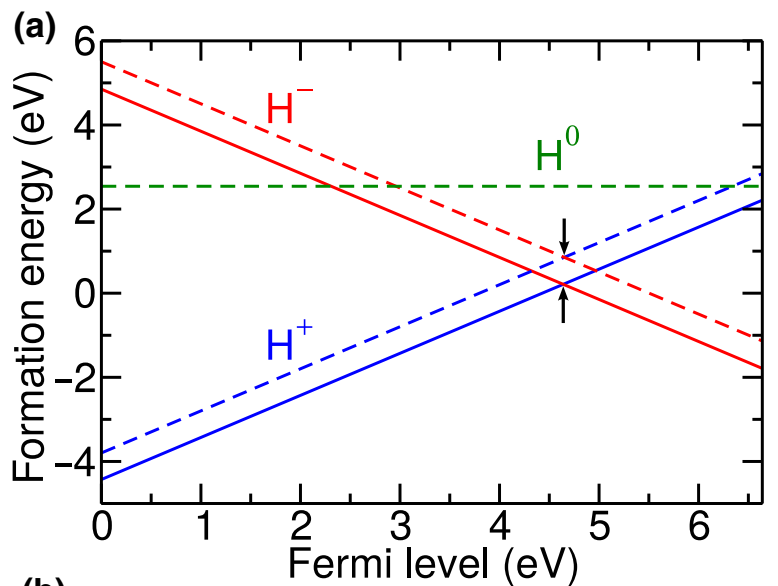

(b)

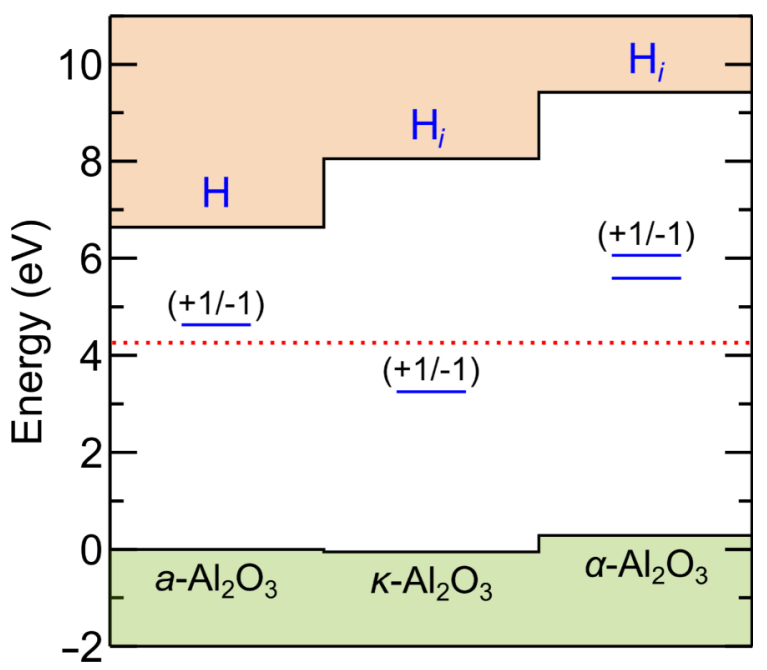

FIG. 2. (a) Average formation energies of hydrogen in $a-\mathrm{Al}_{2} \mathrm{O}_{3}$ as a function of the Fermi energy $\left(\epsilon_{F}\right)$ referred to the VBM, obtained with (solid) and without (dashed) MD simulations. The $+1 /-1$ charge transition level is marked by black arrows. (b) The calculated defect level is compared with corresponding ones in $\kappa-\mathrm{Al}_{2} \mathrm{O}_{3}$ [40] and in $\alpha-\mathrm{Al}_{2} \mathrm{O}_{3}[43,44]$. The band structures of the three phases of alumina are aligned through the $2 s$ level of twofold coordinated $\mathrm{O}$ atoms following Ref. [46]. The universal hydrogen level (red dotted) of Ref. [74] is included through the alignment between GaAs and $a-\mathrm{Al}_{2} \mathrm{O}_{3}$ measured in Refs. [31-33].

of $\mathrm{Al}_{2} \mathrm{O}_{3}[40,43,44]$. One notices that the level found in the amorphous oxide differs noticeably from both results obtained with crystalline models. Interestingly, the former falls within $0.4 \mathrm{eV}$ of the universal hydrogen level of Van de Walle and Neugebauer [74], while the latter differ from this level by more than $1 \mathrm{eV}$.

Experimental work has revealed that an ultrathin layer of $a-\mathrm{Al}_{2} \mathrm{O}_{3}$ deposited on hematite can greatly enhance its performance in splitting water [24]. However, hydroxyl ions in water may penetrate into the voids of $a-\mathrm{Al}_{2} \mathrm{O}_{3}$, and corrode the overlayer. With the aim of clarifying the nature 


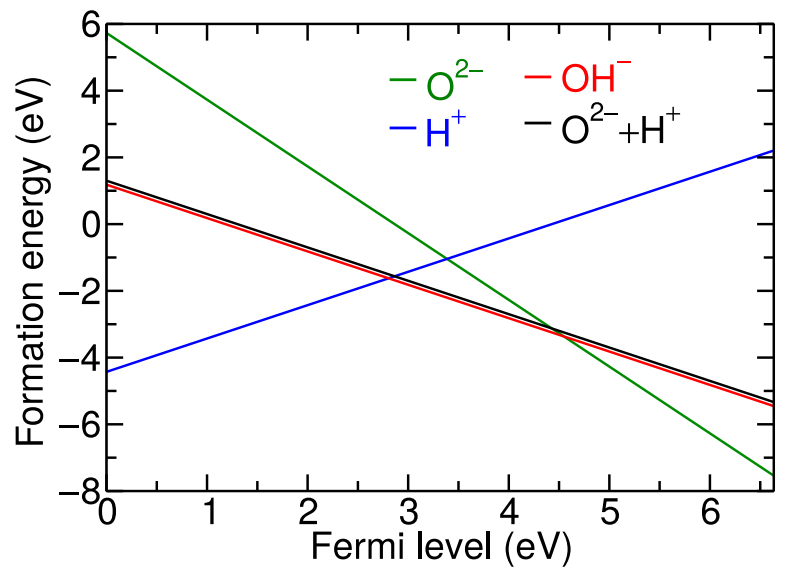

FIG. 3. Average formation energies of interstitial $\mathrm{OH}^{-}, \mathrm{H}^{+}$, and $\mathrm{O}^{2-}$ in $a-\mathrm{Al}_{2} \mathrm{O}_{3}$ as a function of Fermi level referred to the VBM, as obtained upon MD runs. The sum of the formation energies of $\mathrm{H}^{+}$and $\mathrm{O}^{2-}$ is also given (black) to be compared with that of $\mathrm{OH}^{-}$(red).

and the potential impact of hydroxyl ions, we include this impurity in our study and consider two charge states $\left(\mathrm{OH}^{-}\right.$and $\left.\mathrm{OH}^{0}\right)$. Upon MD simulations, the interstitial $\mathrm{OH}^{-}$in $a-\mathrm{Al}_{2} \mathrm{O}_{3}$ is found to merge with the amorphous network, the inserted $\mathrm{O}$ atom bonding to two or three $\mathrm{Al}$ atoms. The obtained configurations precisely correspond to those of $\mathrm{H}^{+}$in $a-\mathrm{Al}_{2} \mathrm{O}_{3}$ [cf. Figs. 1(a) and 1(b)]. The full assimilation of the $\mathrm{OH}^{-}$into the amorphous structure is also supported by the energetics. Indeed, Fig. 3 shows that the formation energy of $\mathrm{OH}^{-}$barely differs from the sum of the formation energies of $\mathrm{O}^{2-}$ and $\mathrm{H}^{+}$. Insofar that $\mathrm{OH}^{-}$ is equivalent to the combination of $\mathrm{H}^{+}$and $\mathrm{O}^{2-}$, there are no single-particle energy levels in the band gap associated with $\mathrm{OH}^{-}$. As far as $\mathrm{OH}^{0}$ is concerned, the same behavior is observed as for $\mathrm{OH}^{-}$. Inspection of the lowest unoccupied molecular orbital (LUMO) reveals that the extra hole is found in a localized state shared by two $\mathrm{O}$ atoms of the amorphous oxide. Full relaxation of the structure at the HSE level also confirms this picture.

\section{B. Carbon}

We investigate carbon as a possible impurity in $a-\mathrm{Al}_{2} \mathrm{O}_{3}$, as metal-organic precursors are often used in the ALD technique when growing this oxide $[30,75,76]$. In monoclinic $\mathrm{HfO}_{2}$, carbon has been suggested to occur in various configurations with the charge imbalance being compensated by an additional defect, such as an oxygen vacancy [77]. In order to broadly explore carbon-related configurations in $a-\mathrm{Al}_{2} \mathrm{O}_{3}$, the carbon impurity is positioned at the centers of 10 different voids after which the geometry is optimized by performing MD. This procedure is repeated for different total charges $Q$ of the simulation cell. Since carbon atoms assume even oxidation states in their oxide (e.g., $\mathrm{CO}$ and $\mathrm{CO}_{2}$ ) and hydride (e.g., $\mathrm{CH}_{4}$ and $\mathrm{C}_{2} \mathrm{H}_{4}$ ) molecules, we start our investigation by first considering the total charge $Q=+4,+2,0,-2$, and -4 . It is important to realize that the nominal charge $q$ carried by the carbon impurity and appearing in the definition of the formation energy in Eq. (1) does not necessarily correspond to the total charge $Q$, as the added charge could localize elsewhere in the simulation cell.

The configurations of the carbon impurity resulting from our investigation for each total charge $Q$ are shown in Fig. 4. For $Q=0$, we identify two kinds of structures. In one of them, the $\mathrm{C}$ impurity shows $s p^{3}$ hybridization and bonds to two oxygen atoms and two aluminium atoms [cf. Fig. 4(d)]. In the other one, the C impurity is $s p^{2}$ hybridized and shows a first-neighbor shell with one double-bonded $\mathrm{O}$ atom and two single-bonded $\mathrm{Al}$ atoms [cf. Fig. 4(c)]. For $Q=-2$ and $Q=-4$, we find carbon in $s p^{3}$ configurations, with either three $\mathrm{Al}$ atoms and one $\mathrm{O}$ oxygen atom or four $\mathrm{Al}$ atoms in the first-neighbor
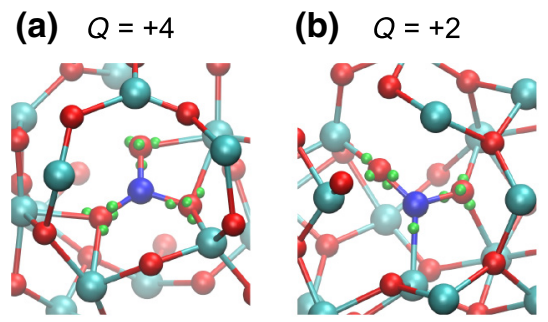

(c) $Q=0$
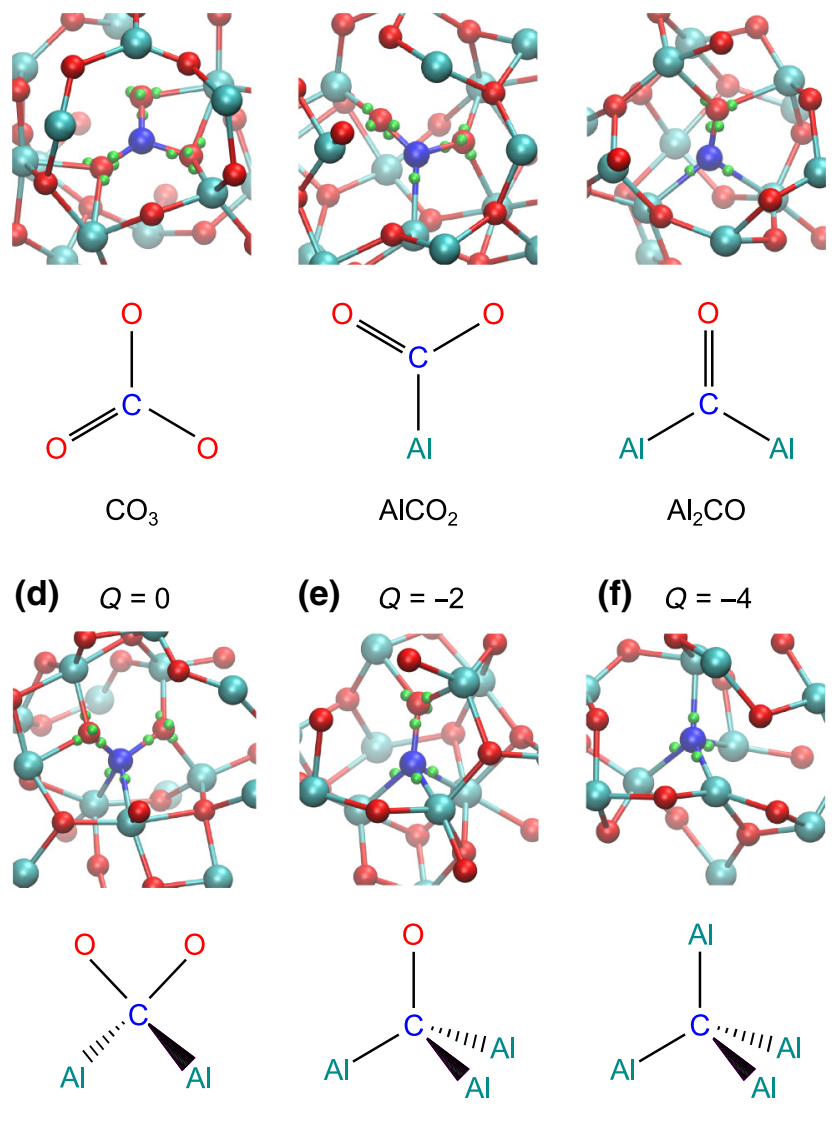

(f) $Q=-4$
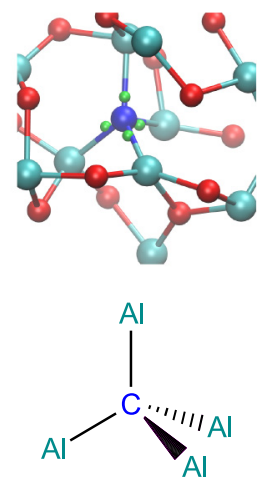

$\mathrm{Al}_{2} \mathrm{CO}_{2}$

$\mathrm{Al}_{3} \mathrm{CO}$

FIG. 4. Carbon-related defect configurations and their skeletal formulas, as obtained with total charge $Q=+4,+2,0,-2$, and -4 . In the atomic configurations, $\mathrm{Al}, \mathrm{O}$, and $\mathrm{C}$ atoms are shown in cyan, red, and blue, respectively. In addition, the centers of the relevant maximally localized Wannier functions are indicated by small green spheres. 


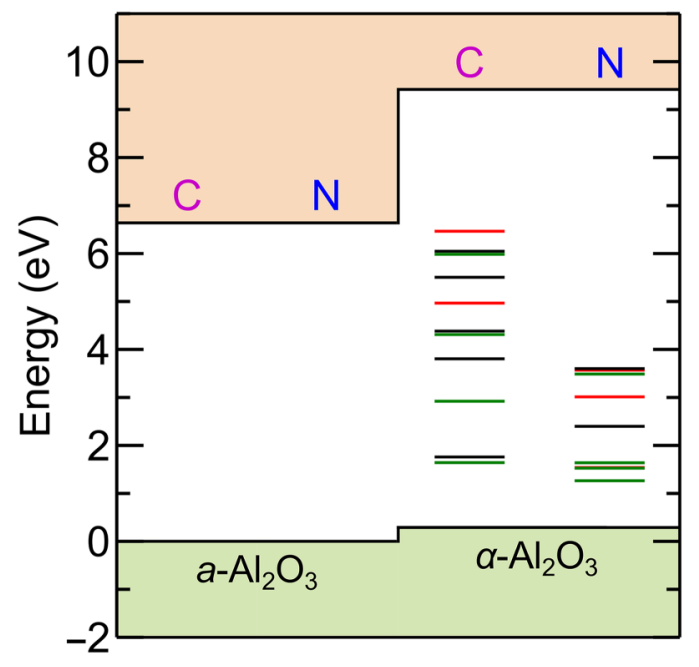

FIG. 5. Absence of charge transition levels of carbon and nitrogen impurities in $a-\mathrm{Al}_{2} \mathrm{O}_{3}$ compared with the levels for the same impurities in $\alpha-\mathrm{Al}_{2} \mathrm{O}_{3}$ reported in Ref. [39]. The latter include defect levels from substitutional sites to $\mathrm{Al}$ (red), substitutional sites to $\mathrm{O}$ (green) and interstitital sites (black). The alignment between $a-\mathrm{Al}_{2} \mathrm{O}_{3}$ and $\alpha-\mathrm{Al}_{2} \mathrm{O}_{3}$ is taken from Ref. [46].

shell, respectively. For $Q=+2$ and $Q=+4$, the carbon impurity is $s p^{2}$ hybridized. In the case $Q=+2$, the firstneighbor shell of the carbon atom consists of one aluminium atom and two oxygen atoms, one of the latter being double bonded, i.e., showing a $\pi$ bond in addition to a $\sigma$ bond. For $Q=+4$, the defect configuration corresponds to a planar $\mathrm{CO}_{3}$ structure, in which one of the $\mathrm{O}$ atoms is double bonded.

In order to rationalize the electronic structure of these defect configurations, we adopt an analysis based on maximally localized Wannier functions (WF) [78], which yields a real-space representation of the electron localization. The centers of these WFs are indicated by small green spheres in Fig. 4. Such a WF analysis allows us to distinguish the nature of the chemical bonds (single vs double bonds), and hence to determine the nominal charge state of the $\mathrm{C}$ impurity. The WF analysis enables electron counting, which reveals that four electrons can be assigned to the carbon impurity in all defect configurations (cf. Fig. 4), corresponding to a nominally neutral defect state with $q=0$. Since all the identified defect states are locally neutral, there are no thermodynamic charge transition levels in the band gap. This important result is illustrated in Fig. 5, where the absence of any charge transition level in $a-\mathrm{Al}_{2} \mathrm{O}_{3}$ is contrasted with the multitude of charge transition levels found for the carbon impurity in crystalline $\alpha-\mathrm{Al}_{2} \mathrm{O}_{3}$ [39]. We note that the nominal charge of the defect corresponds to the charge added to the simulation cell in the case of crystalline materials. The differences in Fig. 5 highlight that the properties of defects in an amorphous oxide

cannot be inferred by relying on the study of crystalline counterparts.

From the configurations found in Fig. 4, we note that the number of $\mathrm{O}$ atoms in the first-neighbor shell reduces with $Q$ decreasing from $Q=+4$ to $Q=-4$, suggesting a connection between total charge and available $\mathrm{O}$ atoms. This is consistent with a previous study on intrinsic defects in $a-\mathrm{Al}_{2} \mathrm{O}_{3}$, in which it was found that adding or removing $\mathrm{O}^{2-}$ just produces a defect-free nonstoichiometric oxide $\left(a-\mathrm{Al}_{2} \mathrm{O}_{3 \pm \delta}\right)$ [15]. Following these lines, the charge imbalance resulting from $Q \neq q$ can be associated with the addition or removal of $\mathrm{O}^{2-}$ ions to the core of the defect, similar in spirit to the dopant compensation found in $\mathrm{HfO}_{2}$ [77].

Let us focus, for instance, on the case $Q=+4$. In this case, a neutral defect with $q=0$ is obtained by considering that two $\mathrm{O}^{2-}$ ions of the amorphous structure should actually be considered as an inherent part of the defect, as illustrated graphically in Fig. 6. We, therefore, effectively focus on a neutral defect core unit composed of $\mathrm{C}^{4+}$ and two $\mathrm{O}^{2-}$. The formation energy of such a neutral defect unit can then be expressed with respect to a host consisting of $\mathrm{Al}_{2} \mathrm{O}_{3}$ with two missing $\mathrm{O}^{2-}$ ions:

$$
\begin{aligned}
E_{f}\left[\mathrm{C}^{4+} \oplus 2 \mathrm{O}^{2-}\right]= & E_{\mathrm{tot}}\left[\mathrm{Al}_{2} \mathrm{O}_{3} \oplus \mathrm{C}^{4+}\right]-\mu_{C}-2 \mu_{O} \\
& -E_{\mathrm{tot}}\left[\mathrm{Al}_{2} \mathrm{O}_{3} \ominus 2 \mathrm{O}^{2-}\right],
\end{aligned}
$$

where $E_{\text {tot }}\left[\mathrm{Al}_{2} \mathrm{O}_{3} \oplus \mathrm{C}^{4+}\right]$ refers to the total energy of the simulation cell with the carbon impurity and $Q=+4$, and $E_{\text {tot }}\left[\mathrm{Al}_{2} \mathrm{O}_{3} \ominus 2 \mathrm{O}^{2-}\right]$ to the total energy of a pristine amorphous system of the same size from which two $\mathrm{O}^{2-}$ ions have been removed. Following the same rationale, defect core units can be established for the other values of $Q$ and have been summarized in Table I. We give the corresponding formation energies explicitly:

$$
\begin{aligned}
E_{f}\left[\mathrm{C}^{2+} \oplus \mathrm{O}^{2-}\right]= & E_{\mathrm{tot}}\left[\mathrm{Al}_{2} \mathrm{O}_{3} \oplus \mathrm{C}^{2+}\right]-\mu_{C}-\mu_{O} \\
& -E_{\text {tot }}\left[\mathrm{Al}_{2} \mathrm{O}_{3} \ominus \mathrm{O}^{2-}\right],
\end{aligned}
$$

$$
E_{f}\left[\mathrm{C}^{0}\right]=E_{\mathrm{tot}}\left[\mathrm{Al}_{2} \mathrm{O}_{3} \oplus \mathrm{C}^{0}\right]-\mu_{C}-E_{\mathrm{tot}}\left[\mathrm{Al}_{2} \mathrm{O}_{3}\right]
$$

Initial state

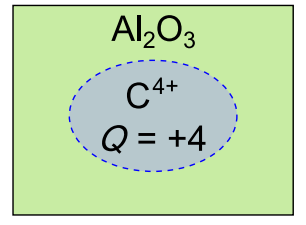

FIG. 6. Schematic representation of charge compensation induced by the insertion of carbon in the simulation cell under the condition of total charge $Q=+4$. 


$$
\begin{aligned}
E_{f}\left[\mathrm{C}^{2-} \ominus \mathrm{O}^{2-}\right]= & E_{\mathrm{tot}}\left[\mathrm{Al}_{2} \mathrm{O}_{3} \oplus \mathrm{C}^{2-}\right]-\mu_{C}+\mu_{O} \\
& -E_{\mathrm{tot}}\left[\mathrm{Al}_{2} \mathrm{O}_{3} \oplus \mathrm{O}^{2-}\right], \\
E_{f}\left[\mathrm{C}^{4-} \ominus 2 \mathrm{O}^{2-}\right]= & E_{\mathrm{tot}}\left[\mathrm{Al}_{2} \mathrm{O}_{3} \oplus \mathrm{C}^{4-}\right]-\mu_{C}+2 \mu_{O} \\
& -E_{\mathrm{tot}}\left[\mathrm{Al}_{2} \mathrm{O}_{3} \oplus 2 \mathrm{O}^{2-}\right] .
\end{aligned}
$$

A general expression for Eqs. (4)-(8) can be cast in the form

$$
\begin{aligned}
E_{f}\left[\mathrm{C}^{Q} \ominus n \mathrm{O}^{2-}\right]= & E_{\mathrm{tot}}\left[\mathrm{Al}_{2} \mathrm{O}_{3} \oplus \mathrm{C}^{Q}\right]-\mu_{C}+n \mu_{O} \\
& -E_{\text {tot }}\left[\mathrm{Al}_{2} \mathrm{O}_{3} \oplus n \mathrm{O}^{2-}\right],
\end{aligned}
$$

where $n=-(Q-q) / 2$, with $q=0$ and $Q=+4,+2,0$, -2 , and -4 . In Eq. (9), all quantities are known except the last term, $E_{\text {tot }}\left[\mathrm{Al}_{2} \mathrm{O}_{3} \oplus n \mathrm{O}^{2-}\right]$, with $n=-2,-1,0,+1$, and +2 . Such terms can be related to the formation energy of $n \mathrm{O}^{2-}$ ions:

$$
\begin{aligned}
E_{f}\left[n \mathrm{O}^{2-}\right]= & E_{\mathrm{tot}}\left[\mathrm{Al}_{2} \mathrm{O}_{3} \oplus n \mathrm{O}^{2-}\right]-n \mu_{O}-E_{\mathrm{tot}}\left[\mathrm{Al}_{2} \mathrm{O}_{3}\right] \\
& -2 n\left(\epsilon_{F}+\varepsilon_{v}\right),
\end{aligned}
$$

where finite-size corrections and alignment terms have been omitted for clarity. Assuming linearity, we further express the formation energy of $n \mathrm{O}^{2-}$ ions in terms of that of a single $\mathrm{O}^{2-}$ ion:

$$
E_{f}\left[n \mathrm{O}^{2-}\right]=n \cdot E_{f}\left[\mathrm{O}^{2-}\right]
$$

where the formation of a single $\mathrm{O}^{2-}$ ion can be expressed as [15]

$$
\begin{aligned}
E_{f}\left[\mathrm{O}^{2-}\right]= & E_{\mathrm{tot}}\left[\mathrm{Al}_{2} \mathrm{O}_{3} \oplus \mathrm{O}^{2-}\right]-\mu_{O}-E_{\mathrm{tot}}\left[\mathrm{Al}_{2} \mathrm{O}_{3}\right] \\
& -2\left(\epsilon_{F}+\varepsilon_{v}\right) .
\end{aligned}
$$

Combining Eqs. (10)-(12), we obtain the following expression in terms of total energies that can explicitly be calculated:

$$
\begin{aligned}
E_{\text {tot }}\left[\mathrm{Al}_{2} \mathrm{O}_{3} \oplus n \mathrm{O}^{2-}\right]= & n \cdot E_{\text {tot }}\left[\mathrm{Al}_{2} \mathrm{O}_{3} \oplus \mathrm{O}^{2-}\right] \\
& -(n-1) \cdot E_{\text {tot }}\left[\mathrm{Al}_{2} \mathrm{O}_{3}\right] .
\end{aligned}
$$

Our analysis shows that the defect core units contain a variable number of oxygen atoms. Therefore, their defect formation energies show a different dependence on the oxygen chemical potential $\mu_{O}$, as can be seen from Eqs. (4)-(8). To study this dependence, we allow the oxygen chemical potential to vary from oxygen-rich conditions to oxygen-poor conditions. In oxygen-rich conditions, the chemical potential is set to half the total energy of an isolated $\mathrm{O}_{2}$ molecule: $\mu_{O}^{\text {rich }}=\frac{1}{2} E_{\text {tot }}\left[\mathrm{O}_{2}\right]$. In oxygen-poor conditions, $\mu_{O}$ is set by taking $\mu_{\mathrm{Al}}$ from $\mathrm{Al}$ metal and by
TABLE I. Charge in the simulation cell $Q$, nominal defect charge $q$, inferred defect core unit and observed atomic structure for the carbon impurity in $a-\mathrm{Al}_{2} \mathrm{O}_{3}$.

\begin{tabular}{llcc}
\hline \hline$Q$ & $q$ & Core unit & Atomic structure \\
\hline+4 & 0 & $\mathrm{C}^{4+} \oplus 2 \mathrm{O}^{2-}$ & $\mathrm{CO}_{3}$ \\
+2 & 0 & $\mathrm{C}^{2+} \oplus \mathrm{O}^{2-}$ & $\mathrm{AlCO}_{2}$ \\
0 & 0 & $\mathrm{C}^{0}$ & $\mathrm{Al}_{2} \mathrm{CO}_{2}$ and $\mathrm{Al}_{2} \mathrm{CO}$ \\
-2 & 0 & $\mathrm{C}^{2-} \ominus \mathrm{O}^{2-}$ & $\mathrm{Al}_{3} \mathrm{CO}$ \\
-4 & 0 & $\mathrm{C}^{4-} \ominus 2 \mathrm{O}^{2-}$ & $\mathrm{Al}_{4} \mathrm{C}$ \\
\hline \hline
\end{tabular}

imposing the equilibrium condition between $\mu_{O}$ and $\mu_{\mathrm{Al}}$ in $\mathrm{Al}_{2} \mathrm{O}_{3}$. This gives

$$
\mu_{O}^{\text {poor }}=\frac{E_{\text {tot }}^{\mathrm{fu}}\left[\mathrm{Al}_{2} \mathrm{O}_{3}\right]-2 E_{\mathrm{tot}}^{\mathrm{at}}[\mathrm{Al}]}{3},
$$

where $E_{\text {tot }}^{\mathrm{fu}}\left[\mathrm{Al}_{2} \mathrm{O}_{3}\right]$ is the total energy per formula unit for our bulk $a-\mathrm{Al}_{2} \mathrm{O}_{3}$ model and $E_{\text {tot }}^{\text {at }}[\mathrm{Al}]$ the total energy per atom for Al metal, which we calculate using a face-centered cubic bulk. Taking $\mu_{O}^{\text {rich }}$ as reference, we determine $\mu_{O}^{\text {poor }}$ to be $-5.33 \mathrm{eV}$.

In Fig. 7, we display the formation energies of C-related defects in $a-\mathrm{Al}_{2} \mathrm{O}_{3}$ as a function of oxygen chemical potential. As $\mu_{O}$ decreases from 0 to $-5.33 \mathrm{eV}$, the most stable defect configurations sequentially change from $\mathrm{CO}_{3}$ to $\mathrm{Al}_{3} \mathrm{CO}$, and $\mathrm{Al}_{4} \mathrm{C}$. In particular, we note that the two configurations found for $Q=0$, i.e., $\mathrm{Al}_{2} \mathrm{CO}$ and $\mathrm{Al}_{2} \mathrm{CO}_{2}$, which differ in formation energy by only $0.18 \mathrm{eV}$, are both metastable. This result is consistent with experimental FTIR observations, which have identified the coexistence of $\mathrm{C}=\mathrm{O}$ and $\mathrm{O}-\mathrm{C}-\mathrm{O}$ moieties [79]. It is also of interest to compare the formation energies obtained for the amorphous with corresponding ones obtained in Ref. [39] for the crystalline phase of $\alpha-\mathrm{Al}_{2} \mathrm{O}_{3}$. This comparison can be

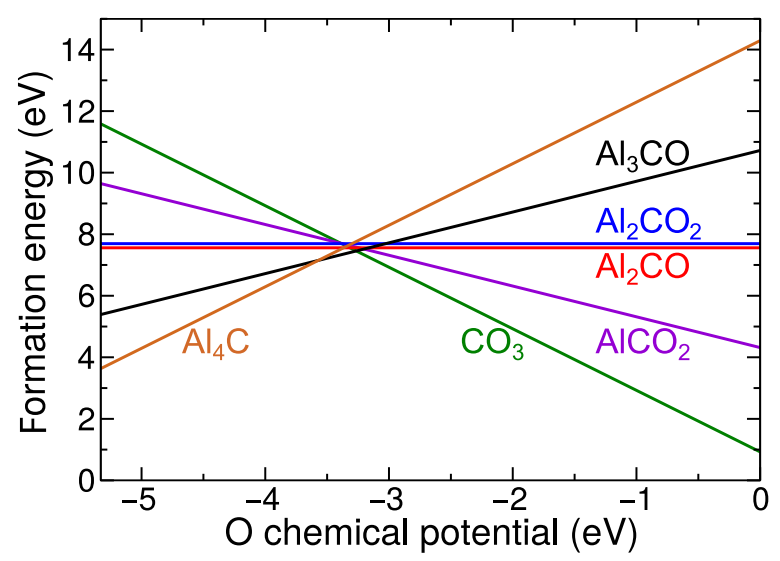

FIG. 7. Formation energies of various defect configurations related to the carbon impurity as a function of oxygen chemical potential. The latter is referred to its value in oxygen-rich conditions. 


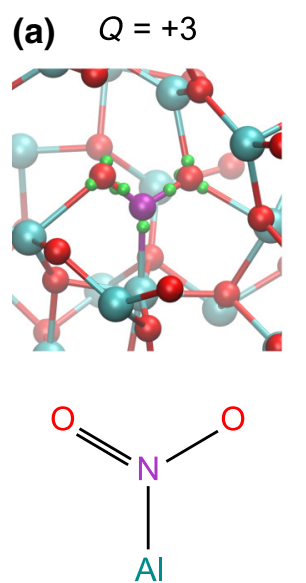

$\mathrm{AlNO}_{2}$
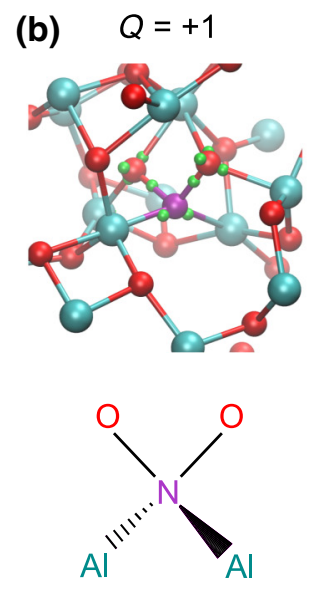

$\mathrm{Al}_{2} \mathrm{NO}_{2}$
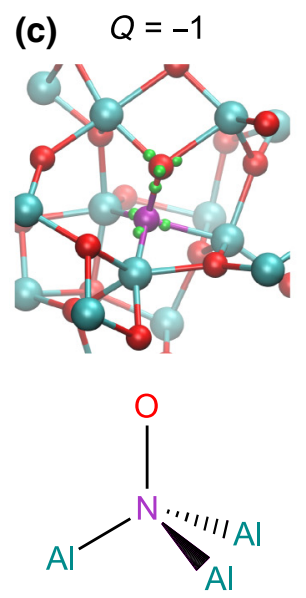

$\mathrm{Al}_{3} \mathrm{NO}$
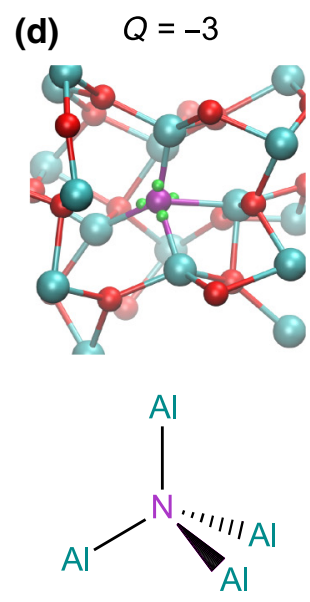

$\mathrm{Al}_{4} \mathrm{~N}$
FIG. 8. Nitrogen-defect-related configurations and their skeletal formulas, as obtained with total charge $Q=+3,+1,-1$, and -3 . In the atomic configurations, $\mathrm{Al}$, $\mathrm{O}$, and $\mathrm{N}$ atoms are shown in cyan, red and purple, respectively. In addition, the centers of the relevant maximally localized Wannier functions are indicated by small green spheres. made for the neutral $\mathrm{O}$ interstitial at $\mu_{O}=-0.65 \mathrm{eV}$, for which we calculate a formation energy of about $2.2 \mathrm{eV}$ (cf. Fig. 7), much lower than the value of $\sim 9.5 \mathrm{eV}$ found for the crystal [39].

For the carbon-related defects identified here, we further investigate the DOS to determine the occurrence of singleelectron energy levels in the band gap. In our scheme, such single-particle levels can be taken as a good approximation of vertical charge transition levels since the adopted hybrid functional accurately reproduces the band gap of $a-\mathrm{Al}_{2} \mathrm{O}_{3}$ [80]. For the $\mathrm{CO}_{3}$ and $\mathrm{AlCO}_{2}$ configurations, there are no such energy levels in the gap, in analogy to the $\mathrm{CO}_{3}$ defect in $\mathrm{HfO}_{2}$ [77]. At variance, the $\mathrm{Al}_{2} \mathrm{CO}$ and $\mathrm{Al}_{2} \mathrm{CO}_{2}$ structures give rise to an occupied defect state at $\sim 2.0 \mathrm{eV}$ above the VBM. Similarly, two and three occupied defect states occur in the range from 1.5 to $3.0 \mathrm{eV}$ above the $\mathrm{VBM}$ for $\mathrm{Al}_{3} \mathrm{CO}$ and $\mathrm{Al}_{4} \mathrm{C}$, respectively. The occurrence of such states is consistent with the experimental finding that photocurrents are induced by subband-gap photons in amorphous samples of anodic-barrier $\mathrm{Al}_{2} \mathrm{O}_{3}$, which contain a sizeable concentration of carbon impurities [79].

To complete our investigation of carbon-related defects, we also consider the case of odd values of total charge $Q$. Upon MD, we find that for all odd values of $Q$ carbon defect states show an unpaired electron. Next, we investigate a double-sized simulation cell containing two such carbon defects and perform further MD. In all cases, we observe disproportionation with the two odd-Q-valued defects transforming to the carbon defect configurations found above for $Q-1$ and $Q+1$ (cf. Fig. 4). This transition is accompanied by a significant decrease in total energy certifying that $2 E_{\mathrm{tot}}^{Q}>E_{\mathrm{tot}}^{Q-1}+$ $E_{\text {tot }}^{Q+1}$ for odd values of $Q$. On this basis, the carbon configurations resulting from odd values of $Q$ can conclusively be ruled out as thermodynamically stable defect configurations.

\section{Nitrogen}

Nitrogen is often incorporated into $a-\mathrm{Al}_{2} \mathrm{O}_{3}$ either intentionally or unintentionally due to the use of metal-organic precursors during growth. Therefore, we study this impurity in $a-\mathrm{Al}_{2} \mathrm{O}_{3}$ following the same protocol adopted for carbon. However, unlike carbon, the isolated $\mathrm{N}$ atom carries five valence electrons and we thus start our investigation by considering odd values of $Q$, i.e., $Q=+5,+3,+1,-1$, and -3 . The nitrogen-related configurations that are identified as $Q$ is varied are shown in Fig. 8. In particular, we find $\mathrm{AlNO}_{2}, \mathrm{Al}_{2} \mathrm{NO}_{2}, \mathrm{Al}_{3} \mathrm{NO}$, and $\mathrm{Al}_{4} \mathrm{~N}$ for $Q=+3,+1,-1$, and -3 , respectively. We note that the nitrate-like $\mathrm{NO}_{3}$ configuration does not occur. For $Q=+5$, we find the same $\mathrm{AlNO}_{2}$ defect configuration obtained for $Q=+3$ [cf. Fig. 8(a)], the two extra holes being trapped through the formation of a peroxy linkage [15]. More generally, one can note that the nitrogen defect configurations identified for a total charge $Q$ correspond to the carbon ones for $Q^{\prime}=Q-1$, accounting in this way for the fact that $\mathrm{N}$ possesses one extra valence electron compared to $\mathrm{C}$. In the $\mathrm{AlNO}_{2}$ configuration, the $\mathrm{N}$ impurity shows a $s p^{2}$ hybridization, with a double bond between $\mathrm{N}$ and one of the $\mathrm{O}$ atoms [see skeletal formula in Fig. 8(a)]. At variance, the nitrogen impurity is $s p^{3}$ hybridized in the other configurations. Inspection of the DOS reveals that the $\mathrm{AlNO}_{2}$ configuration shows an unoccupied single-particle energy level at $4.8 \mathrm{eV}$ above the $\mathrm{VBM}$, corresponding to an antibonding $\pi$ orbital. The $\mathrm{Al}_{2} \mathrm{NO}_{2}, \mathrm{Al}_{3} \mathrm{NO}$, and $\mathrm{Al}_{4} \mathrm{~N}$ configurations give rise to occupied single-particle energy levels in the lower part of the band gap, within $1 \mathrm{eV}$ from the VBM.

Adopting the electron counting rule based on a WF analysis, we find that in all configurations, four electrons are associated with the nitrogen impurity. This implies that the nominal charge state of the impurity is always $q=+1$, and consequently, no thermodynamic charge transition level associated with the nitrogen impurity occurs in $a-\mathrm{Al}_{2} \mathrm{O}_{3}$. 
TABLE II. Charge in the simulation cell $Q$, nominal defect charge $q$, inferred defect core unit and observed atomic structure for the nitrogen impurity in $a-\mathrm{Al}_{2} \mathrm{O}_{3}$.

\begin{tabular}{lccc}
\hline \hline$Q$ & $q$ & Core unit & Atomic structure \\
\hline+3 & +1 & $\mathrm{~N}^{3+} \oplus \mathrm{O}^{2-}$ & $\mathrm{AlNO}_{2}$ \\
+1 & +1 & $\mathrm{~N}^{1+}$ & $\mathrm{Al}_{2} \mathrm{NO}_{2}$ \\
-1 & +1 & $\mathrm{~N}^{1-} \ominus \mathrm{O}^{2-}$ & $\mathrm{Al}_{3} \mathrm{NO}$ \\
-3 & +1 & $\mathrm{~N}^{3-} \ominus 2 \mathrm{O}^{2-}$ & $\mathrm{Al}_{4} \mathrm{~N}$ \\
\hline \hline
\end{tabular}

As for carbon, this conclusion contrasts with results found for crystalline phases (cf. Fig. 5) [39].

To account for the local defect charge $q=+1$, we define defect core units by including a suitable number of $\mathrm{O}^{2-}$ atoms (cf. Table II). Their formation energies are then calculated following the same rationale used for the carbon impurity through the following general expression:

$$
\begin{aligned}
E_{f}\left(\mathrm{~N}^{Q} \ominus n \mathrm{O}^{2-}\right)= & E_{\text {tot }}\left[\mathrm{Al}_{2} \mathrm{O}_{3} \oplus \mathrm{N}^{Q}\right]-\mu_{N}+n \mu_{O} \\
& -E_{\text {tot }}\left[\mathrm{Al}_{2} \mathrm{O}_{3} \oplus n \mathrm{O}^{2-}\right]+\varepsilon_{F}+\varepsilon_{v},
\end{aligned}
$$

where $n=-(Q-q) / 2$ with $q=+1$ and $Q=+3,+1$, -1 , and -3 . In Eq. (15), finite-size corrections and alignment terms have been omitted for clarity. Fixing the Fermi level at the VBM, we display these formation energies as a function of oxygen chemical potential in Fig. 9. It is seen that the most stable defect configurations rapidly lose $\mathrm{O}$ atoms from their first-neighbor shell as the oxygen chemical potential moves away from oxygen-rich conditions. In particular, for $\mu_{O}<-1.3 \mathrm{eV}$, the prevalent defect structure in $a-\mathrm{Al}_{2} \mathrm{O}_{3}$ is $\mathrm{Al}_{4} \mathrm{~N}$. This observation is quite consistent with the conclusion reported in Ref. [39] that nitrogen incorporates into the oxide by replacing $\mathrm{O}$ atoms $\left(\mathrm{N}_{O}\right)$.

We also investigate the nitrogen impurity in our model of $a-\mathrm{Al}_{2} \mathrm{O}_{3}$ by setting the total charge $Q$ to even values, i.e., $Q=+4,+2,0$, and -2 . For $Q=+4$, we find the same defect configuration $\mathrm{AlNO}_{2}$ found in the case of $Q=+3$, but with an extra hole in the valence band. For $Q=+2,0$ and -2 , we find defect structures with unpaired electrons on the nitrogen impurity, but all of them undergo disproportionation to structures pertaining to $Q+1$ and $Q-1$ when doubling the simulation cell in an analogous way as seen for odd values of $Q$ in the case of the carbon impurity. Hence, we conclude that no other nitrogen defect structures occur than those reported in Fig. 8.

\section{ALIGNMENT TO SEMICONDUCTOR BAND EDGES}

In this section, we discuss the possible electrical activity of the defect levels identified in this work. For this purpose, we first align the band structure of $a-\mathrm{Al}_{2} \mathrm{O}_{3}$ to the band edges of three semiconductors ( $\mathrm{GaAs}, \mathrm{GaN}$, and

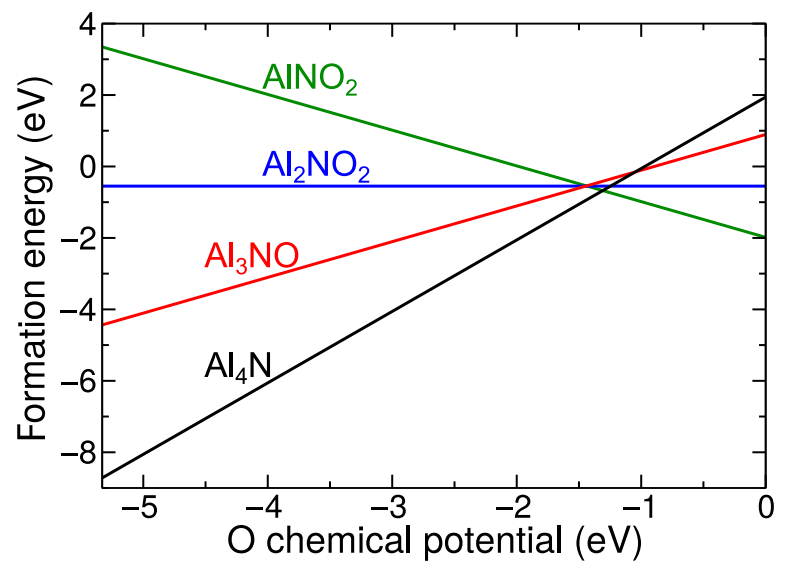

FIG. 9. Formation energies of various defect configurations related to the nitrogen impurity as a function of oxygen chemical potential. The latter is referred to its value in oxygen-rich conditions. The formation energies are determined for the Fermi level fixed at the VBM.

$\alpha-\mathrm{Fe}_{2} \mathrm{O}_{3}$ ), which are relevant for technological applications. The Fermi level is bound to the range that encompasses the band gap and its position determines the stable charge states that can be found in the oxide. For GaAs and $\mathrm{GaN}$, we take the band alignment with respect to $a-\mathrm{Al}_{2} \mathrm{O}_{3}$ from photoemission experiments [31-33,81], which propose valence band offsets of 3.8 and $1.1 \mathrm{eV}$, respectively. For $\alpha-\mathrm{Fe}_{2} \mathrm{O}_{3}$, we rely on the band alignment put forward in Ref. [82]. The band alignment obtained in this way is illustrated in Fig. 10.

Additionally, we include the charge transition levels determined for hydrogen, carbon and nitrogen impurities in $a-\mathrm{Al}_{2} \mathrm{O}_{3}$. Since carbon and nitrogen do not give any defect level in the band gap, this sums up considering only the $-1 /+1$ charge transition level of hydrogen.

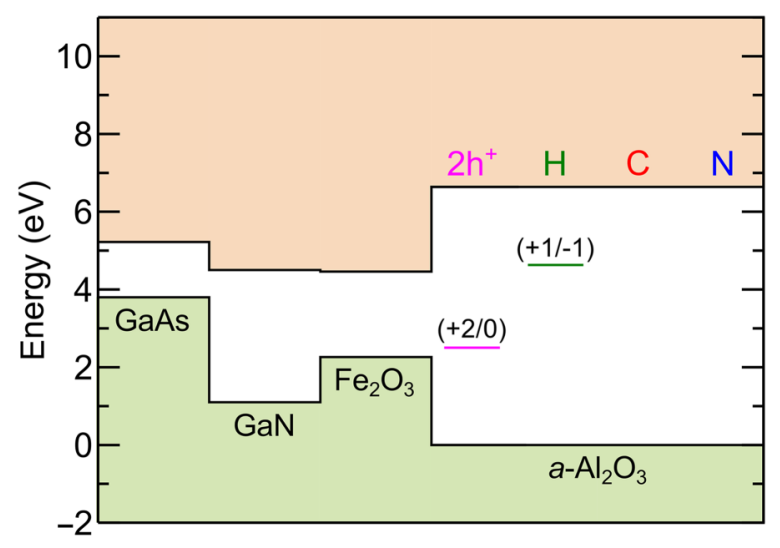

FIG. 10. Band alignment between three different semiconductors, i.e., GaAs, GaN, $\alpha-\mathrm{Fe}_{2} \mathrm{O}_{3}$, and $a-\mathrm{Al}_{2} \mathrm{O}_{3}$. The charge transition levels for hydrogen, carbon and nitrogen found in this work are indicated together with the double-hole polaron $\left(2 \mathrm{~h}^{+}\right)$, corresponding to the formation of a peroxy linkage [15]. The band alignment is taken from experiment $[31-33,81,82]$. 
To complete the picture, we also include the $+2 / 0$ charge transition level associated with the self-trapped double polaron, as inferred in Ref. [15] from the study of intrinsic defects in $a-\mathrm{Al}_{2} \mathrm{O}_{3}$.

For GaAs, only the $-1 /+1$ charge transition level of hydrogen lies in the range of the band gap. Hence, hydrogen impurities in $a-\mathrm{Al}_{2} \mathrm{O}_{3}$ may contribute to gate leakage currents and degrade the performance of MOS devices based on GaAs. For $\mathrm{GaN}$ and $\alpha-\mathrm{Fe}_{2} \mathrm{O}_{3}$, the hydrogen defect level in $a-\mathrm{Al}_{2} \mathrm{O}_{3}$ is found in the proximity of the conduction band minimum, and might constitute a trap for free electron carriers. Furthermore, this suggests that hydrogen is in a positively charged state for most Fermi levels in the band gaps of these materials.

Also, the $+2 / 0$ charge transition level associated with the peroxy linkage falls in the range of the band gap for $\mathrm{GaN}$ and $\alpha-\mathrm{Fe}_{2} \mathrm{O}_{3}$. This level might thus constitute a conduction channel for hole leakage in p-type doping conditions for these materials. In particular, in the case of $\alpha-\mathrm{Fe}_{2} \mathrm{O}_{3}$, this level could explain the observations in Ref. [24], in which hole conduction was observed across an overlayer of $a-\mathrm{Al}_{2} \mathrm{O}_{3}$ on hematite. The $+2 / 0$ level of the double polaron lies at only $0.25 \mathrm{eV}$ from the VBM of $\alpha-\mathrm{Fe}_{2} \mathrm{O}_{3}$. This alignment favors the injection of holes from $\alpha-\mathrm{Fe}_{2} \mathrm{O}_{3}$ into $a-\mathrm{Al}_{2} \mathrm{O}_{3}$, which could diffuse across the oxide through the sequential formation and breaking of $\mathrm{O}-\mathrm{O}$ pairs, as proposed for hole diffusion in $a-\mathrm{TiO}_{2}$ [83]. Furthermore, the small offset between the VBM of $\alpha-\mathrm{Fe}_{2} \mathrm{O}_{3}$ and the $+2 / 0$ level would not significantly affect the energy of photogenerated holes and thus preserve the catalytic properties of $\alpha-\mathrm{Fe}_{2} \mathrm{O}_{3}$ in the oxidation of water.

\section{CONCLUSION}

In conclusion, we investigate the structural and electronic properties of hydrogen, carbon and nitrogen impurities in $a-\mathrm{Al}_{2} \mathrm{O}_{3}$. We devote particular attention to finding the most stable structural configurations through extensive ab initio molecular dynamics in various charge states. In the case of hydrogen, our approach does not lead to qualitative differences with respect to calculations based on straight structural relaxations. Hydrogen is found to be amphoteric with a $+1 /-1$ charge transition level lying at $\sim 4.6 \mathrm{eV}$ above the VBM. Hydroxyl groups incorporated in $a-\mathrm{Al}_{2} \mathrm{O}_{3}$ are shown to give rise to defect states equivalent to those of the hydrogen impurity. At variance, in the case of carbon and nitrogen impurities, we find a series of structural configurations, which vary depending on the total charge set in the simulation cell. To identify the nominal charge of the defect, we adopt an electron counting scheme based on maximally localized WF. In this way, we infer that carbon and nitrogen impurities in $a-\mathrm{Al}_{2} \mathrm{O}_{3}$ only give rise to neutral and singly positive charge states, respectively. This leads to the astonishing observation that these impurities do not give any charge transition level in
$a-\mathrm{Al}_{2} \mathrm{O}_{3}$, in stark contrast with studies on crystalline models predicting a multitude of levels. To account for the local charge of the impurity, we then redefine the core unit of the defect by which the obtained configurations naturally depend on the oxygen chemical potential. In oxygen-poor conditions, both the carbon and the nitrogen favor bonding to $\mathrm{Al}$ atoms, while they tend to form single and double bonds with oxygen atoms as the oxygen chemical potential increases.

From our study, a picture emerges by which only two significant charge transition levels occur in $a-\mathrm{Al}_{2} \mathrm{O}_{3}$, namely, the $+1 /-1$ level of hydrogen and the intrinsic $+2 / 0$ level related to the peroxy linkage. Relying on the experimental band alignment, we can position these levels with respect to the band edges of three semiconductors of technological relevance (GaAs, GaN, and $\alpha-\mathrm{Fe}_{2} \mathrm{O}_{3}$ ). The $+1 /-1$ level of hydrogen in $a-\mathrm{Al}_{2} \mathrm{O}_{3}$ falls in the band-gap range of these semiconductors and can thus degrade the electronic properties in MOS devices or trap free electron carriers. On the other hand, the intrinsic $+2 / 0$ level is suitably positioned with respect to the valence band maximum of $\mathrm{GaN}$ and $\alpha-\mathrm{Fe}_{2} \mathrm{O}_{3}$ for favoring hole transport across $a-\mathrm{Al}_{2} \mathrm{O}_{3}$, thereby providing a rationale for experimental observations [24].

Overall, the present approach reveals the importance of identifying the most stable structural configurations when studying defects in amorphous oxides. Furthermore, our study highlights the importance of properly defining the nominal charge of the defect and its core unit. We expect the procedure outlined in this work to be transferable to other impurities as well as to other amorphous oxides.

\section{ACKNOWLEDGMENTS}

This work has been performed in the context of the National Center of Competence in Research (NCCR) "Materials' Revolution: Computational Design and Discovery of Novel Materials (MARVEL)" of the Swiss National Science Foundation. We used computational resources of CSCS, SCITAS, and CSEA-EPFL.

[1] T. Kuwabara, T. Nakayama, K. Uozumi, T. Yamaguchi, and K. Takahashi, Highly durable inverted-type organic solar cell using amorphous titanium oxide as electron collection electrode inserted between ITO and organic layer, Sol. Energy Mater. Sol. Cells 92, 1476 (2008).

[2] H. Chiang, J. Wager, R. Hoffman, J. Jeong, and D. A. Keszler, High mobility transparent thin-film transistors with amorphous zinc tin oxide channel layer, Appl. Phys. Lett. 86, 013503 (2005).

[3] K. Nomura, H. Ohta, A. Takagi, T. Kamiya, M. Hirano, and H. Hosono, Room-temperature fabrication of transparent flexible thin-film transistors using amorphous oxide semiconductors, Nature 432, 488 (2004). 
[4] D. Guyomard, C. Sigala, A. de Gal La Salle, and Y. Piffard, New amorphous oxides as high capacity negative electrodes for lithium batteries: The $\mathrm{Li}_{x} \mathrm{MVO}_{4}(\mathrm{M}=$ $\mathrm{Ni}, \mathrm{Co}, \mathrm{Cd}, \mathrm{Zn} ; 1<x \leq 8)$ series, J. Power Sources 68 , 692 (1997).

[5] Y. Piffard, F. Leroux, D. Guyomard, J.-L. Mansot, and M. Tournoux, The amorphous oxides $\mathrm{MnV}_{2} \mathrm{O}_{6+\delta}(0<\delta<1)$ as high capacity negative electrode materials for lithium batteries, J. Power Sources 68, 698 (1997).

[6] A. Mehonic, M. Munde, W. Ng, M. Buckwell, L. Montesi, M. Bosman, A. Shluger, and A. Kenyon, Intrinsic resistance switching in amorphous silicon oxide for high performance $\mathrm{SiO}_{x}$ ReRAM devices, Microelectron. Eng. 178, 98 (2017).

[7] M. Cho, J. H. Kim, C. S. Hwang, H.-S. Ahn, S. Han, and J. Y. Won, Effects of carbon residue in atomic layer deposited $\mathrm{HfO}_{2}$ films on their time-dependent dielectric breakdown reliability, Appl. Phys. Lett. 90, 182907 (2007).

[8] K. Kukli, M. Ritala, M. Leskelä, and J. Jokinen, Atomic layer epitaxy growth of aluminum oxide thin films from a novel $\mathrm{Al}\left(\mathrm{CH}_{3}\right)_{2} \mathrm{Cl}$ precursor and $\mathrm{H}_{2} \mathrm{O}$, J. Vac. Sci. Technol. A 15, 2214 (1997).

[9] S. Lee and H. Jeon, Characteristics of an $\mathrm{Al}_{2} \mathrm{O}_{3}$ thin film deposited by a plasma enhanced atomic layer deposition method using $\mathrm{N}_{2} \mathrm{O}$ plasma, Electron. Mater. Lett. 3, 17 (2007).

[10] W. G. Lee, S. I. Woo, J. C. Kim, S. H. Choi, and K. H. Oh, Preparation and properties of amorphous $\mathrm{TiO}_{2}$ thin films by plasma enhanced chemical vapor deposition, Thin Solid Films 237, 105 (1994).

[11] C. Wenger, M. Lukosius, I. Costina, R. Sorge, J. Dabrowski, H.-J. Müssig, S. Pasko, and C. Lohe, Investigation of atomic vapour deposited $\mathrm{TiN} / \mathrm{HfO}_{2} / \mathrm{SiO}_{2}$ gate stacks for MOSFET devices, Microelectron. Eng. 85, 1762 (2008).

[12] C. Freysoldt, B. Grabowski, T. Hickel, J. Neugebauer, G. Kresse, A. Janotti, and C. G. Van de Walle, First-principles calculations for point defects in solids, Rev. Mod. Phys. 86, 253 (2014).

[13] H.-P. Komsa, T. T. Rantala, and A. Pasquarello, Finite-size supercell correction schemes for charged defect calculations, Phys. Rev. B 86, 045112 (2012).

[14] J. Godet, P. Broqvist, and A. Pasquarello, Hydrogen in $\mathrm{Si}(100)-\mathrm{SiO}_{2}-\mathrm{HfO}_{2}$ gate stacks: Relevant charge states and their location, Appl. Phys. Lett. 91, 262901 (2007).

[15] Z. Guo, F. Ambrosio, and A. Pasquarello, Oxygen defects in amorphous $\mathrm{Al}_{2} \mathrm{O}_{3}$ : A hybrid functional study, Appl. Phys. Lett. 109, 062903 (2016).

[16] P. Ye, G. Wilk, J. Kwo, B. Yang, H.-J. Gossmann, M. Frei, S. Chu, J. Mannaerts, M. Sergent, M. Hong, K. Ng, and J. Bude, GaAs MOSFET with oxide gate dielectric grown by atomic layer deposition, IEEE Electron Device Lett. 24, 209 (2003).

[17] P. D. Ye, B. Yang, K. K. Ng, J. Bude, G. D. Wilk, S. Halder, and J. C. M. Hwang, GaN metal-oxide-semiconductor highelectron-mobility-transistor with atomic layer deposited $\mathrm{Al}_{2} \mathrm{O}_{3}$ as gate dielectric, Appl. Phys. Lett. 86, 063501 (2005).

[18] H. Zhao, D. Shahrjerdi, F. Zhu, M. Zhang, H.-S. Kim, I. OK, J. H. Yum, S. I. Park, S. K. Banerjee, and J. C. Lee,
Gate-first inversion-type InP metal-oxide-semiconductor field-effect transistors with atomic-layer-deposited $\mathrm{Al}_{2} \mathrm{O}_{3}$ gate dielectric, Appl. Phys. Lett. 92, 233508 (2008).

[19] Y. Xuan, Y. Wu, H. Lin, T. Shen, and P. Ye, Submicrometer inversion-type enhancement-mode InGaAs MOSFET with atomic-layer-deposited $\mathrm{Al}_{2} \mathrm{O}_{3}$ as gate dielectric, IEEE Electron Device Lett. 28, 935 (2007).

[20] P. Kordos, D. Gregušová, R. Stoklas, K. Čičo, and J. Novák, Improved transport properties of $\mathrm{Al}_{2} \mathrm{O}_{3} / \mathrm{AlGaN} / \mathrm{GaN}$ metaloxide-semiconductor heterostructure field-effect transistor, Appl. Phys. Lett. 90, 123513 (2007).

[21] X. Zhang, I. Belharouak, L. Li, Y. Lei, J. W. Elam, A. Nie, X. Chen, R. S. Yassar, and R. L. Axelbaum, Structural and electrochemical study of $\mathrm{Al}_{2} \mathrm{O}_{3}$ and $\mathrm{TiO}_{2}$ coated $\mathrm{Li}_{1.2} \mathrm{Ni}_{0.13} \mathrm{Mn}_{0.54} \mathrm{Co}_{0.13} \mathrm{O}_{2}$ cathode material using $\mathrm{ALD}$, Adv. Energy Mater. 3, 1299 (2013).

[22] J. W. Kim, D. H. Kim, D. Y. Oh, H. Lee, J. H. Kim, J. H. Lee, and Y. S. Jung, Surface chemistry of $\mathrm{LiNi}_{0.5} \mathrm{Mn}_{1.5} \mathrm{O}_{4}$ particles coated by $\mathrm{Al}_{2} \mathrm{O}_{3}$ using atomic layer deposition for lithium-ion batteries, J. Power Sources 274, 1254 (2015).

[23] J.-T. Lee, F.-M. Wang, C.-S. Cheng, C.-C. Li, and C.-H. Lin, Low-temperature atomic layer deposited $\mathrm{Al}_{2} \mathrm{O}_{3}$ thin film on layer structure cathode for enhanced cycle ability in lithium-ion batteries, Electrochim. Acta 55, 4002 (2010).

[24] F. Le Formal, N. Tétreault, M. Cornuz, T. Moehl, M. Grätzel, and K. Sivula, Passivating surface states on water splitting hematite photoanodes with alumina overlayers, Chem. Sci. 2, 737 (2011).

[25] Y. Chang, F. Ducroquet, E. Gautier, O. Renault, J. Legrand, J. Damlencourt, and F. Martin, Surface preparation and post thermal treatment effects on interface properties of thin $\mathrm{Al}_{2} \mathrm{O}_{3}$ films deposited by ALD, Microelectron. Eng. 72, 326 (2004).

[26] H. Lin, P. Ye, and G. Wilk, Current-transport properties of atomic-layer-deposited ultrathin $\mathrm{Al}_{2} \mathrm{O}_{3}$ on GaAs, Solid-State Electron. 50, 1012 (2006).

[27] B. Shin, D. Choi, J. S. Harris, and P. C. McIntyre, Preatomic layer deposition surface cleaning and chemical passivation of (100) $\mathrm{In}_{0.2} \mathrm{Ga}_{0.8}$ As and deposition of ultrathin $\mathrm{Al}_{2} \mathrm{O}_{3}$ gate insulators, Appl. Phys. Lett. 93, 052911 (2008).

[28] R. L. Puurunen, Surface chemistry of atomic layer deposition: A case study for the trimethylaluminum/water process, J. Appl. Phys. 97, 9 (2005).

[29] M. J. Young, C. B. Musgrave, and S. M. George, Growth and characterization of $\mathrm{Al}_{2} \mathrm{O}_{3}$ atomic layer deposition films on $\mathrm{sp}^{2}$-graphitic carbon substrates using $\mathrm{NO}_{2}$ /trimethylaluminum pretreatment, ACS Appl. Mater. Interfaces 7, 12030 (2015).

[30] M. Groner, F. Fabreguette, J. Elam, and S. George, Lowtemperature $\mathrm{Al}_{2} \mathrm{O}_{3}$ atomic layer deposition, Chem. Mater. 16, 639 (2004).

[31] M. L. Huang, Y. C. Chang, C. H. Chang, T. D. Lin, J. Kwo, T. B. Wu, and M. Hong, Energy-band parameters of atomic-layer-deposition $\mathrm{Al}_{2} \mathrm{O}_{3} / \mathrm{InGaAs}$ heterostructure, Appl. Phys. Lett. 89, 012903 (2006).

[32] J. Ahn, I. Geppert, M. Gunji, M. Holland, I. Thayne, M. Eizenberg, and P. C. McIntyre, Titania/alumina bilayer gate insulators for InGaAs metal-oxide-semiconductor devices, Appl. Phys. Lett. 99, 232902 (2011). 
[33] I. Krylov, D. Ritter, and M. Eizenberg, The physical origin of dispersion in accumulation in InGaAs based metal oxide semiconductor gate stacks, J. Appl. Phys. 117, 174501 (2015).

[34] T. V. Perevalov, O. E. Tereshenko, V. A. Gritsenko, V. A. Pustovarov, A. P. Yelisseyev, C. Park, J. H. Han, and C. Lee, Oxygen deficiency defects in amorphous $\mathrm{Al}_{2} \mathrm{O}_{3}$, J. Appl. Phys. 108, 013501 (2010).

[35] C. Århammar, A. Pietzsch, N. Bock, E. Holmström, C. M. Araujo, J. Grsjö, S. Zhao, S. Green, T. Peery, F. Hennies, S. Amerioun, A. Föhlisch, J. Schlappa, T. Schmitt, V. N. Strocov, G. A. Niklasson, D. C. Wallace, J.-E. Rubensson, B. Johansson, and R. Ahuja, Unveiling the complex electronic structure of amorphous metal oxides, Proc. Natl. Acad. Sci. USA 108, 6355 (2011).

[36] D. Liu, Y. Guo, L. Lin, and J. Robertson, First-principles calculations of the electronic structure and defects of $\mathrm{Al}_{2} \mathrm{O}_{3}$, J. Appl. Phys. 114, 083704 (2013).

[37] H. Momida, S. Nigo, G. Kido, and T. Ohno, Effect of vacancy-type oxygen deficiency on electronic structure in amorphous alumina, Appl. Phys. Lett. 98, 042102 (2011).

[38] V. V. Afanas'ev, W. C. Wang, F. Cerbu, O. Madia, M. Houssa, and A. Stesmans, Spectroscopy of deep gap states in high-k insulators, ECS Trans. 64, 17 (2014).

[39] M. Choi, J. L. Lyons, A. Janotti, and C. G. Van de Walle, Impact of carbon and nitrogen impurities in high- $\kappa$ dielectrics on metal-oxide-semiconductor devices, Appl. Phys. Lett. 102, 142902 (2013).

[40] J. R. Weber, A. Janotti, and C. G. Van de Walle, Point defects in $\mathrm{Al}_{2} \mathrm{O}_{3}$ and their impact on gate stacks, Microelectron. Eng. 86, 1756 (2009).

[41] L. Gordon, H. Abu-Farsakh, A. Janotti, and C. G. Van de Walle, Hydrogen bonds in $\mathrm{Al}_{2} \mathrm{O}_{3}$ as dissipative twolevel systems in superconducting qubits, Sci. Rep. 4, 07590 (2014).

[42] K. Xiong, J. Robertson, and S. J. Clark, Behavior of hydrogen in wide band gap oxides, J. Appl. Phys. 102, 083710 (2007).

[43] H. Li and J. Robertson, Behaviour of hydrogen in wide band gap oxides, J. Appl. Phys. 115, 203708 (2014).

[44] A. M. Holder, K. D. Osborn, C. J. Lobb, and C. B. Musgrave, Bulk and Surface Tunneling Hydrogen Defects in Alumina, Phys. Rev. Lett. 111, 065901 (2013).

[45] M. Cho, D. S. Jeong, J. Park, H. B. Park, S. W. Lee, T. J. Park, C. S. Hwang, G. H. Jang, and J. Jeong, Comparison between atomic-layer-deposited $\mathrm{HfO}_{2}$ films using $\mathrm{O}_{3}$ or $\mathrm{H}_{2} \mathrm{O}$ oxidant and $\mathrm{Hf}\left[\mathrm{N}\left(\mathrm{CH}_{3}\right)_{2}\right]_{4}$ precursor, Appl. Phys. Lett. 85, 5953 (2004).

[46] D. Colleoni, G. Miceli, and A. Pasquarello, Band alignment and chemical bonding at the GaAs $/ \mathrm{Al}_{2} \mathrm{O}_{3}$ interface: A hybrid functional study, Appl. Phys. Lett. 107, 211601 (2015).

[47] A. Alkauskas, P. Broqvist, and A. Pasquarello, Defect levels through hybrid density functionals: Insights and applications, Phys. Status Solidi B 248, 775 (2011).

[48] C. Freysoldt, J. Neugebauer, and C. G. Van de Walle, Fully Ab Initio Finite-size Corrections for Charged-defect Supercell Calculations, Phys. Rev. Lett. 102, 016402 (2009).

[49] J. Van de Vondele, M. Krack, F. Mohamed, M. Parrinello, T. Chassaing, and J. Hutter, Quickstep: Fast and accurate density functional calculations using a mixed Gaussian and plane waves approach, Comput. Phys. Commun. 167, 103 (2005).

[50] S. Goedecker, M. Teter, and J. Hutter, Separable dual-space Gaussian pseudopotentials, Phys. Rev. B 54, 1703 (1996).

[51] C. Hartwigsen, S. Goedecker, and J. Hutter, Relativistic separable dual-space Gaussian pseudopotentials from $\mathrm{H}$ to Rn, Phys. Rev. B 58, 3641 (1998).

[52] T. H. Dunning, Gaussian basis sets for use in correlated molecular calculations. I. The atoms boron through neon and hydrogen, J. Chem. Phys. 90, 1007 (1989).

[53] J. Van de Vondele and J. Hutter, Gaussian basis sets for accurate calculations on molecular systems in gas and condensed phases, J. Chem. Phys. 127, 114105 (2007).

[54] J. P. Perdew, K. Burke, and M. Ernzerhof, Generalized Gradient Approximation Made Simple, Phys. Rev. Lett. 77, 3865 (1996).

[55] J. Heyd, G. E. Scuseria, and M. Ernzerhof, Hybrid functionals based on a screened Coulomb potential, J. Chem. Phys. 118, 8207 (2003).

[56] J. Heyd, G. E. Scuseria, and M. Ernzerhof, Erratum: Hybrid functionals based on a screened Coulomb potential [J. Chem. Phys. 1188207 (2003)], J. Chem. Phys. 124, 219906 (2006).

[57] H.-P. Komsa, P. Broqvist, and A. Pasquarello, Alignment of defect levels and band edges through hybrid functionals: Effect of screening in the exchange term, Phys. Rev. B 81, 205118 (2010).

[58] R. H. French, Electronic band structure of $\mathrm{Al}_{2} \mathrm{O}_{3}$, with comparison to Alon and AIN, J. Am. Ceram. Soc. 73, 477 (1990).

[59] M. Guidon, F. Schiffmann, J. Hutter, and J. Van de Vondele, $A b$ initio molecular dynamics using hybrid density functionals, J. Chem. Phys. 128, 214104 (2008).

[60] M. Guidon, J. Hutter, and J. Van de Vondele, Robust periodic Hartree-Fock exchange for large-scale simulations using Gaussian basis sets, J. Chem. Theory Comput. 5, 3010 (2009).

[61] M. Guidon, J. Hutter, and J. Van de Vondele, Auxiliary density matrix methods for Hartree-Fock exchange calculations, J. Chem. Theory Comput. 6, 2348 (2010).

[62] P. Lamparter and R. Kniep, Structure of amorphous $\mathrm{Al}_{2} \mathrm{O}_{3}$, Phys. B 234-236, 405 (1997).

[63] Y. Oka, T. Takahashi, K. Okada, and S.-I. Iwai, Structural analysis of anodic alumina films, J. Non-Cryst. Solids 30, 349 (1979).

[64] S.-M. Lee, D. G. Cahill, and T. H. Allen, Thermal conductivity of sputtered oxide films, Phys. Rev. B 52, 253 (1995).

[65] W. G. Hoover, Canonical dynamics: Equilibrium phasespace distributions, Phys. Rev. A 31, 1695 (1985).

[66] S. Nosé, A unified formulation of the constant temperature molecular dynamics methods, J. Chem. Phys. 81, 511 (1984).

[67] H. Li, Y. Guo, and J. Robertson, Hydrogen and the lightinduced bias instability mechanism in amorphous oxide semiconductors, Sci. Rep. 7, 16858 (2017).

[68] P. Broqvist, A. Alkauskas, J. Godet, and A. Pasquarello, First principles investigation of defect energy levels at semiconductor-oxide interfaces: Oxygen vacancies and 
hydrogen interstitials in the $\mathrm{Si}-\mathrm{SiO}_{2}-\mathrm{HfO}_{2}$ stack, J. Appl. Phys. 105, 061603 (2009).

[69] J. Godet and A. Pasquarello, Protons at the $\mathrm{Si}_{-} \mathrm{SiO}_{2}$ interface: A first principle investigation, Microelectron. Eng. 84, 2035 (2007).

[70] J. Godet and A. Pasquarello, Proton diffusion in amorphous $\mathrm{SiO}_{2}$ and hafnium silicate by $A b$ initio molecular dynamics, AIP Conf. Proc. 893, 195 (2007).

[71] J. Godet, F. Giustino, and A. Pasquarello, Proton-induced Fixed Positive Charge at the $\mathrm{Si}(100)-\mathrm{SiO}_{2}$ Interface, Phys. Rev. Lett. 99, 126102 (2007).

[72] J. Godet and A. Pasquarello, Proton Diffusion Mechanism in Amorphous $\mathrm{SiO}_{2}$, Phys. Rev. Lett. 97, 155901 (2006).

[73] J. Godet and A. Pasquarello, Ab initio study of charged states of $\mathrm{H}$ in amorphous $\mathrm{SiO}_{2}$, Microelectron. Eng. 80, 288 (2005).

[74] C. G. Van de Walle and J. Neugebauer, Universal alignment of hydrogen levels in semiconductors, insulators and solutions, Nature 423, 626 (2003).

[75] M. Groner, J. Elam, F. Fabreguette, and S. George, Electrical characterization of thin $\mathrm{Al}_{2} \mathrm{O}_{3}$ films grown by atomic layer deposition on silicon and various metal substrates, Thin Solid Films 413, 186 (2002).

[76] W. Cho, K. Sung, K.-S. An, S. Sook Lee, T.-M. Chung, and $\mathrm{Y}$. Kim, Atomic layer deposition of $\mathrm{Al}_{2} \mathrm{O}_{3}$ thin films using dimethylaluminum isopropoxide and water, J. Vac. Sci. Technol. A 21, 1366 (2003).
[77] H. Li, Y. Guo, and J. Robertson, Dopant compensation in $\mathrm{HfO}_{2}$ and other high $\mathrm{K}$ oxides, Appl. Phys. Lett. 104, 192904 (2014).

[78] N. Marzari, A. A. Mostofi, J. R. Yates, I. Souza, and D. Vanderbilt, Maximally localized wannier functions: Theory and applications, Rev. Mod. Phys. 84, 1419 (2012).

[79] M. González-Castaño, M. Döbeli, V. Araullo-Peters, L. P. Jeurgens, P. Schmutz, and C. Cancellieri, Substrate purity effect on the defect formation and properties of amorphous anodic barrier $\mathrm{Al}_{2} \mathrm{O}_{3}$, J. Electrochem. Soc. 165, C422 (2018).

[80] G. Miceli, W. Chen, I. Reshetnyak, and A. Pasquarello, Nonempirical hybrid functionals for band gaps and polaronic distortions in solids, Phys. Rev. B 97, 121112 (2018).

[81] Y. Hori, C. Mizue, and T. Hashizume, Process conditions for improvement of electrical properties of $\mathrm{Al}_{2} \mathrm{O}_{3} / n-\mathrm{GaN}$ structures prepared by atomic layer deposition, Jpn. J. Appl. Phys. 49, 080201 (2010).

[82] R. van de Krol, Y. Liang, and J. Schoonman, Solar hydrogen production with nanostructured metal oxides, J. Mater. Chem. 18, 2311 (2008).

[83] Z. Guo, F. Ambrosio, and A. Pasquarello, Hole diffusion across leaky amorphous $\mathrm{TiO}_{2}$ coating layers for catalytic water splitting at photoanodes, J. Mater. Chem. A 6, 11804 (2018). 